\title{
Treatment of Urethral/Bladder Neck Stricture After High-Intensity Focused Ultrasound for Prostate Cancer With Holmium: Yttrium-Aluminium-Garnet Laser
}

\author{
Won Jin Cho, Tae Heon Kim ${ }^{1}$, Hyo Serk Lee ${ }^{2}$, Jin Woo Chung ${ }^{1}$, Ha Na Lee ${ }^{3}$ Kyu-Sung Lee ${ }^{1}$ \\ Department of Urology, Chosun University Hospital, Chosun University School of Medicine, Gwangju; \\ ${ }^{1}$ Department of Urology, Samsung Medical Center, Sungkyunkwan University School of Medicine, Seoul; \\ ${ }^{2}$ Department of Urology, Cheil General Hospital \& Women's Healthcare Center, Kwandong University College of Medicine, Seoul; \\ ${ }^{3}$ Department of Urology, Ewha Womans University Medical Center, Seoul Seonam Hospital, Seoul, Korea
}

\begin{abstract}
Purpose: To evaluate the efficacy and safety of the Holmium: yttrium-aluminium-garnet (YAG) laser for the treatment of urethral/bladder neck strictures after high-intensity focused ultrasound for prostate cancer.

Methods: Between February 2007 and July 2010, Holmium: YAG laser urethrotomies were performed in eleven patients for bladder neck strictures or prostatic urethral strictures. The laser was used with a $550-\mu \mathrm{m}$ fiber at $2 \mathrm{~J}$ and frequency 30 to $50 \mathrm{~Hz}$. The medical records were retrospectively reviewed for medical history, perioperative and postoperative data, uroflowmetry, International Prostate Symptoms Score/quality of life, and stricture recurrence.

Results: At a median follow-up of 12.0 months (range, 4 to 35 months), the mean postoperative maximal flow rate and residual volume were improved significantly $(\mathrm{P}<0.05)$. The mean postoperative total, voiding and quality of life of international prostate symptom score were improved significantly $(\mathrm{P}<0.05)$. Of the 11 patients, 7 patients required one treatment, 4 patients two treatment, and 1 patients three treatment. 2 patients who had a documented urinary incontinence prior to the laser treatment subsequently required artificial urinary sphincter implantation and reported satisfaction without developing any recurrent strictures or artificial urinary sphincter erosion. All patients exhibited well-healed strictures and could void without difficulty.

Conclusions: Holmium: YAG laser therapy represents a safe, effective and minimally invasive treatment for urethral/bladder neck strictures occurring secondary to high-intensity focused ultrasound for prostate cancer.
\end{abstract}

Keywords: Transrectal high-intensity focused ultrasound; Holmium; Prostate neoplasms; Urethral stricture; Urinary bladder neck obstruction

\section{INTRODUCTION}

Both the widespread use of prostate specific antigen screening test and the increased push for earlier prostate cancer detection has increased the number of patients diagnosed with localized prostate cancer suitable for curative approach. Radical prostatectomy (RP) is a widely recognized, standardized, curative procedure for organ-confined prostate cancer and is performed by urologists all over the world [1,2]. However, despite excellent long-term survival rates, RP is still associated with significant morbidity. Moreover, RP is also not indicated for patients with life expectancies of less than 10 years as well as individuals who are either not fit for surgery or who are wary of the potential side effects of this surgery [3]. Accordingly, a number of minimally invasive therapies are being developed as alternative modalities, including transrectal high-intensity focused ultrasound (HIFU), which is now indicated for patients with localized, lowgrade prostate cancer or as salvage therapy in cases of cancer
Corresponding author: Kyu-Sung Lee

Department of Urology, Samsung Medical Centre, Sungkyunkwan University School of Medicine, 81 Irwon-ro, Gangnam-gu, Seoul 135-710, Korea Tel: +82-2-3410-3558 / Fax: +82-2-3410-3027 / E-mail: ksleedr@skku.edu Submitted: February 21, 2013 / Accepted after revision: March 18, 2013
This is an Open Access article distributed under the terms of the Creative Commons Attribution Non-Commercial License (http://creativecommons.org/licenses/by-nc/3.0/) which permits unrestricted non-commercial use, distribution, and reproduction in any medium, provided the original work is properly cited. 
recurrence after radiotherapy [4-6].

With the increased incidence of all types of prostate cancer treatment, a significant increase in urinary incontinence, erectile dysfunction and vesicourethral complications has also occurred. Specifically, strictures at the vesicourethral anastomosis or urethral strictures represent relatively common postoperative complications after RP (0.4\%-32\%) and HIFU (1\%-31\%) [7-10]. As these strictures can cause severe voiding dysfunction and often have high rates of recurrence, they have been shown to impact quality of life (QoL) of patients in a markedly negative manner. The optimal treatment for these strictures remains unclear. Several treatment options, including simple or balloon dilatation, endoscopic cold-knife incision, endoscopic electrocautery incision and/or resection, and intermittent self-catheterization have been reported with varying degrees of success and recurrence rate (3\%-87\%) [11-15]. Emerging data now suggested that Holmium: yttrium-aluminium-garnet (YAG) laser endourethrotomy may represent a safe and minimally invasive therapeutic modality in the treatment for strictures of vesicourethral anastomosis secondary to RP [16,17]. HIFU is a technique that uses focused ultrasound to generate areas of intense heat to destroy tissue. So, the theoretical mechanisms of stricture occurring secondary to HIFU may differ from other modalities.

In the current study, we present our clinical experiences to evaluate the efficacy and safety of the Holmium: YAG laser in the treatment of urethral/bladder neck strictures occurring secondary to HIFU for prostate cancer.

\section{MATERIALS AND METHODS}

Between February 2007 and July 2010, the Holmium: YAG laser was used in 11 male patients for the treatment of initial or recurrent urethral/bladder neck strictures that occurred secondary to HIFU for prostate cancer. As defined here, strictures included bladder neck strictures and prostatic urethral strictures. After Institutional Review Board approval, the medical records of these 11 patients were reviewed. A diagnosis of stricture was reached based on clinical history, symptoms, uroflowmetric assessment, urethroscopy and/or urethrography. Perioperative and postoperative data including operative time, complications (if any), period of indwelling urethral catheter use, postoperative hospital stay, and recurrence rates were also evaluated. The treatment efficacy was quantified using uroflowmetric assessment as well as International Prostate Symptom Scores
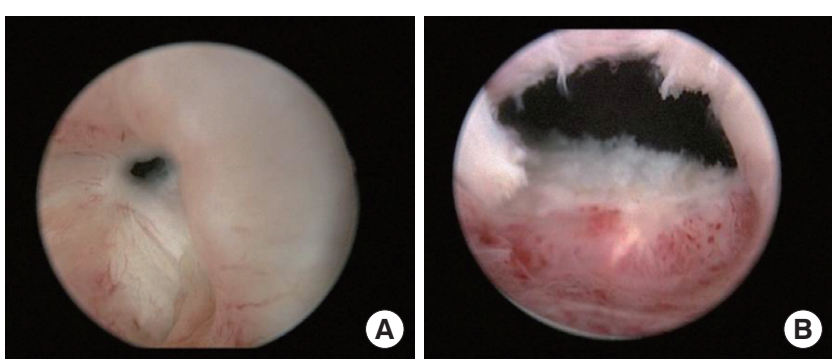

Fig. 1. Endoscopic view of bladder neck before (A) and after (B) treatment with the Holmium: yttrium-aluminium-garnet laser.

(IPSS) and QoL scores. Urinalysis and urine culture were done to document the absence of urinary tract infections.

All surgical treatments were performed under spinal or general anesthesia with patients in the lithotomy position. Using saline irrigation, a rigid endoscope (8-26 F) with a $550-\mu \mathrm{m}$ end-firing laser fiber was passed to the area of stricture, as determined by the caliber of the urethra. Under direct retrograde vision, deep incisions were typically made into the fibrotic scar tissue at the 5 and 7 oclock positions. If necessary, another incision was made into the scar tissue at the 12 oclock or another position. In the cases of bladder neck stricture, the ureteral orifices were identified if possible prior to deep incision. The affected areas were then treated with the Holmium: YAG laser at a setting of $2 \mathrm{~J}$ with frequencies between 30 and $50 \mathrm{~Hz}$ (60-100 W). Ideally, these incisions would open up the lumen, however any remaining scar tissue that appeared to have the potential to hinder urine flow was removed by vaporization (Fig. 1). After the scar tissue was completely excised while sparing healthy tissue and free passage of the endoscope into the bladder was confirmed, a urethral Foley catheter was placed and left for several days.

Statistical significance was determined in all cases by Wilcoxon signed rank test and P-value less than 0.05 were considered statistically significant.

\section{RESULTS}

In total, 11 patients were included in this study, 9 patients were diagnosed with bladder neck strictures and 2 patients prostatic urethral strictures. The patients' preoperative characteristics are summarized in Table 1. One patient had been previously treated for benign prostatic hyperplasia by photoselective vaporization using potassium-titanyl-phosphate laser prior HIFU procedure and 4 patients were treated for voiding difficulty secondary to prostatic debris with transurethral resection prior enroll- 
ment.

The median operation time was 27 minutes (range, 10 to 70 minutes), and there no serious perioperative or postoperative complications were reported. The median time for urethral Foley catheter removal was 3 days (range, 1 to 14 days), and the median postoperative hospital stay was 2 days (range, 1 to 6 days). The median follow-up period after Holmium: YAG laser treatment was 12 months (range, 4 to 35 months).

After treatment, significant improvements were observed in the maximal flow rate $(\mathrm{Qmax})$ and residual urine volume, though not in voided volume. The total IPSS score, voiding

Table 2. Uroflowmetry and IPSS/QoL data before and after treatment

\begin{tabular}{lccc}
\hline Parameters & $\begin{array}{c}\text { Before laser } \\
\text { therapy }\end{array}$ & $\begin{array}{c}\text { After laser } \\
\text { therapy }\end{array}$ & P-value \\
\hline Uroflowmetry & & & \\
$\quad$ Voided volume $(\mathrm{mL})$ & $114.18 \pm 81.75$ & $103.73 \pm 78.03$ & 0.530 \\
$\quad$ Qmax $(\mathrm{mL} / \mathrm{sec})$ & $4.01 \pm 3.21$ & $8.54 \pm 7.94$ & 0.015 \\
$\quad$ Residual volume $(\mathrm{mL})$ & $54.31 \pm 48.86$ & $19.92 \pm 21.82$ & 0.019 \\
IPSS & & & \\
Total score & $22.11 \pm 7.10$ & $13.38 \pm 4.53$ & 0.028 \\
Voiding score & $14.78 \pm 4.06$ & $7.00 \pm 4.90$ & 0.034 \\
$\quad$ Storage score & $7.33 \pm 4.44$ & $6.38 \pm 1.60$ & 0.234 \\
QoL score & $4.67 \pm 1.41$ & $3.00 \pm 1.20$ & 0.017 \\
\hline
\end{tabular}

Qmax, maximal flow rate; IPSS, International Prostate Symptom Score; QoL, quality of life. score and QoL score also improved significantly, however no significant difference occurred in the storage score when compared with the preoperative values (Table 2).

Of the 11 patients enrolled in this study, 7 patients (63.6\%) reported satisfactory results without recurrence after the first Holmium: YAG laser treatment, as determined by subjective symptoms and uroflowmetric assessment. However, 4 patients (36.4\%) did require repeat endoscopic Holmium: YAG laser treatment. The median recurrence time after the first Holmium: YAG laser treatment was 2.5 months (range, 2 to 12 months). Although one patient (9.1\%) did require a third treatment 2 months later, all of these individuals were ultimately satisfied with the end result, as determined by symptoms and uroflowmetric assessment (Table 1).

Of note, 2 patients (18.2\%) did subsequently require artificial urinary sphincter (AUS) implantation for stress urinary incontinence, all of whom had a history of urinary incontinence prior to the initial Holmium: YAG laser treatment. In addition, these had twice been treated with endoscopic Holmium: YAG laser treatment. These underwent AUS implantations 12 months later after last laser treatment and reported satisfaction with their treatment course 6 months later without developing any additional recurrent bladder neck contracture or AUS erosion.

\section{DISCUSSION}

While erectile dysfunction and urinary incontinence are the

Table 1. Patients' characteristics

\begin{tabular}{|c|c|c|c|c|c|c|c|c|}
\hline Patient & $\begin{array}{l}\text { Age } \\
(\mathrm{yr})\end{array}$ & $\begin{array}{c}\text { BMI } \\
\left(\mathrm{kg} / \mathrm{m}^{2}\right)\end{array}$ & $\begin{array}{l}\text { Stricture } \\
\text { site }\end{array}$ & $\begin{array}{l}\text { Stricture diagnosis } \\
\text { after HIFU (mo) }\end{array}$ & $\begin{array}{l}\text { Adjuvant therapy } \\
\text { for prostate cancer }\end{array}$ & $\begin{array}{c}\text { Previous } \\
\text { operation history }\end{array}$ & $\begin{array}{l}\text { Treatment } \\
\text { frequency }\end{array}$ & $\begin{array}{l}\text { Follow-up after } \\
\text { last therapy (mo) }\end{array}$ \\
\hline 1 & 77 & 24.17 & $\mathrm{BN}$ & 3 & - & - & 3 & 4 \\
\hline 2 & 75 & 24.43 & $\mathrm{BN}$ & 8 & - & KTP & 1 & 4 \\
\hline 3 & 71 & 27.47 & $\mathrm{BN}$ & 26 & $\mathrm{RT}$ & TUR & 2 & 18 \\
\hline 4 & 78 & 21.35 & $\mathrm{BN}$ & 13 & - & TUR & 1 & 7 \\
\hline 5 & 66 & 26.52 & $\mathrm{BN}$ & 22 & - & - & 1 & 12 \\
\hline 6 & 68 & 19.67 & $\mathrm{BN}$ & 5 & - & - & 1 & 6 \\
\hline 7 & 72 & 27.8 & $\mathrm{BN}$ & 6 & - & - & 2 & 15 \\
\hline 8 & 74 & 23.74 & PU & 11 & - & - & 1 & 10 \\
\hline 9 & 80 & 18.52 & $\mathrm{BN}$ & 16 & $\mathrm{RT}$ & TUR & 2 & 19 \\
\hline 10 & 77 & 26.10 & $\mathrm{PU}$ & 10 & - & TUR & 1 & 32 \\
\hline 11 & 71 & 22.07 & $\mathrm{BN}$ & 4 & - & - & 1 & 35 \\
\hline
\end{tabular}

HIFU, high-intensity focused ultrasound; BN, bladder neck; PU, prostatic urethra; RT, radiation therapy; KTP, potassium-titanyl-phosphate (KTP) laser photoselective vaporization; TUR, transurethral resection. 
most well described postoperative complications after surgical treatment for prostate cancer, strictures of the vesicourethral anastomosis or urethral strictures also occur frequently, with reported incidences rate ranging from $0.4 \%$ to $32 \%[7,8,16,17]$. Even in experienced hands, these complications are seen occasionally [18]. Stricture at the vesicourethral anastomosis is usually results from scar tissue encircling and narrowing the reconfigured bladder neck. This narrowing can cause significant bladder outlet obstruction and ultimately result in a number of lower urinary tract symptoms, such as weak stream, urine stream spraying, incomplete bladder emptying, frequency, and intermittency. In more severe cases, acute urinary retention may even develop. In cases of HIFU performed for the treatment of prostate cancer, the reported incidences of urethral strictures and/or bladder neck strictures were similar with cases of RP ( $1 \%$ to $31 \%$ ), sloughing of necrotic tissue from the coagulated gland also has the potential to cause urethral strictures and/or bladder neck strictures. During this period of sloughing, patients often complain of dysuria with concomitant irritative and/or obstructive urinary symptoms and eliminate debris through micturition. Therefore, the mechanisms of strictures and treatment results may differ considerably between the treatment modalities for prostate cancer.

To date, the various treatment options for strictures at the vesicourethral anastomosis or urethral strictures after RP for prostate cancer reported in the literature include dilatation with sounds, bougies, balloon catheter and intermittent self-catheterization, endoscopic cold-knife incision, endoscopic electrocautery incision or resection, and open surgery [11-15]. Stricture dilatation was initially proposed as the first treatment modality, however was later found to have limited durable success. Cold-knife stricture incision represents a second option, though as complete resection of the scar is not possible, this modality may not remove enough tissue to prevent future recurrences [19]. After incision, scar tissue can also be resected with an electrocautery loop wire, however this carries the risk of damage to surrounding healthy tissue (including the external sphincter) if too deep a resection is performed [14].

In addition to the modalities described above, several alternative methods have been also evaluated. Of these, laser technology offers the potential advantage of less scar tissue formation via a thermal incision. Data now suggests that rates of treatment success are 36\% and 50\% for the neodymium: YAG laser treatment which has been the most commonly used for this purpose $[20,21]$. These results may be attributed to the physical characteristics of the neodymium: YAG laser itself as laser energy reaches tissue depths between 4 and $5 \mathrm{~mm}$ [22].

First introduced into urologic practice in the early 1990s, the Holmium: YAG laser is a minimally invasive device used as a surgical alternative for many clinical indications, including urinary stone lithotripsy, upper urinary tract tissue ablation, transurethral prostate incision and resection, and neoplasm excision [23]. The Holmium: YAG laser emits a monochrome light wavelength of 2,100 $\mathrm{nm}$ in pulses. As this wavelength is highly absorbed by water and has a shallow penetration depth $<0.5$ $\mathrm{mm}$, it is able to ablate tissue through vaporization with only minimal thermal damage to surrounding healthy tissue and low rates of postoperative scar tissue $[16,17,24]$.

In 2004, Dogra et al. [25] described the use of Holmium: YAG laser for traumatic obliterative urethral stricture, demonstrating excellent results (with a mean Qmax of $20 \mathrm{~mL} / \mathrm{sec}$ ) in $65.51 \%$ of cases and acceptable results in $31.03 \%$ of cases. Choi et al. [26] reported the use of endoscopic Holmium: YAG laser in 14 patients with incomplete urethral strictures secondary to inflammation or trauma, whereby endoscopic Holmium: YAG laser urethrotomy proved a safe and effective minimally invasive therapeutic modality in stricture less than $2 \mathrm{~cm}$ in length. In another case series, Lagerveld et al. [17] presented 10 patients with strictures of vesicourethral anastomosis secondary to RP (including six individuals previously treated with dilatation, clean intermittent self-catheterization, and cold-knife urethrotomy), who Holmium: YAG laser treatment were able to void without difficulty and did not require re-treatment. Similarly, Eltahawy et al. [16] reported a success rate of $83 \%$ in treating recurrent anastomotic stenosis following RP using Holmium: YAG laser and concomitant steroid injections. In an another prospective randomized clinical trial comparing low-power Holmium: YAG laser urethrotomy with cold-knife incision for the treatment of urethral strictures, Atak et al. [27] demonstrated that Holmium: YAG laser therapy provides shorter operative time and lower recurrence rates without any statistically significant differences in Qmax versus the cold-knife technique. In the data presented here, we also observed significant improvements in the uroflowmetric assessment and IPSS without any problems with urinary continence.

Although all of the case series regarding Holmium: YAG laser endourethrotomy after prostatectomy have limited numbers of enrolled patients and relatively short follow-up period, the rate of recurrence after Holmium: YAG laser treatment appears relatively lower than with cold-knife incision $[16,17,28]$. 
Routinely follow-up appointments at regular short intervals were performed soon after the initial treatment with concomitant patient counseling, in order to screen for symptoms of recurrence. In total, 4 of 11 patients (36.4\%) did ultimately show evidence of recurrence of bladder neck strictures, necessitating retreatment. The treatment of recurrences was repeat endoscopic treatment with the Holmium: YAG laser. Moreover, one patient underwent a third procedure via the same protocol for additional recurrences. Notably, previously published data reports that this treatment was associated with lower recurrence rates ( $0 \%$ to $29 \%$ ) than observed in the results presented here (36.4\%) $[16,17,27]$. Of these patients who did develop recurrent strictures, 2 had concomitant radiation therapy for prostate cancer. We contend that these adjuvant therapies for prostate cancer may affect the overall rates of recurrence. Additionally, none of the previous studies included patients with a history of HIFU. Eventually, repeat treatments with Holmium: YAG laser improved the patients' symptoms and urine flow and all patients showed no recurrence even in the latest follow-up.

In the results presented here, the median time to the recurrence was 2.5 months (range, 2 to 12 months). As all recurrences occurred within the first year postoperatively, we recommend closer patient follow-up during this period.

This study has several limitations. First, various laser power (60-100 W) were used here, as per the previous experience of the performing surgeon and the intraoperative situation, though similar variances $(5-40 \mathrm{~W})$ were also present in other previous laser urethrotomy case series [16,17,24-27]. Moreover, the higher laser powers that were used in the present study may also have affected the results. Second, the number of patients included in the present study was relatively small (11 patients) and the follow-up period (median, 12.0 months; range, 4 to 35 months) was relatively short. However this was also the case in other similar studies regarding Holmium: YAG laser urethrotomy for the treatment of strictures secondary to RP for prostate cancer. Specifically, these studies also only enrolled a small number of patients (10 to 24 patients) and had follow-up periods ranging from 3 to 72 months [16,17]. However, little is known about post-HIFU bladder outlet obstruction. To our knowledge, our study is the first use of the Holmium: YAG laser in the urethral/bladder neck strictures after HIFU for prostate cancer.

In conclusion, Holmium: YAG laser therapy may represent a safe, effective and minimally invasive treatment for urethral/ bladder neck strictures after HIFU for prostate cancer. Holmi- um: YAG laser therapy offers the advantages of minimal trauma to peripheral local tissue and allows the preservations of the continence mechanism. Future prospective studies with longer follow-up period and larger cohorts that compare Holmium: YAG laser treatment with other therapeutic modalities will be clearly needed to further confirm these findings.

\section{CONFLICT OF INTEREST}

No potential conflict of interest relevant to this article was reported.

\section{REFERENCES}

1. Thompson I, Thrasher JB, Aus G, Burnett AL, Canby-Hagino ED, Cookson MS, et al. Guideline for the management of clinically localized prostate cancer: 2007 update. J Urol 2007;177:2106-31.

2. Aus G, Abbou CC, Bolla M, Heidenreich A, Schmid HP, van Poppel $\mathrm{H}$, et al. EAU guidelines on prostate cancer. Eur Urol 2005;48: 546-51.

3. Augustin H, Hammerer P, Graefen M, Palisaar J, Noldus J, Fernandez S, et al. Intraoperative and perioperative morbidity of contemporary radical retropubic prostatectomy in a consecutive series of 1243 patients: results of a single center between 1999 and 2002. Eur Urol 2003;43:113-8.

4. Lukka H, Waldron T, Chin J, Mayhew L, Warde P, Winquist E, et al. High-intensity focused ultrasound for prostate cancer: a systematic review. Clin Oncol (R Coll Radiol) 2011;23:117-27.

5. Crouzet S, Rebillard X, Chevallier D, Rischmann P, Pasticier G, Garcia G, et al. Multicentric oncologic outcomes of high-intensity focused ultrasound for localized prostate cancer in 803 patients. Eur Urol 2010;58:559-66.

6. Illing RO, Leslie TA, Kennedy JE, Calleary JG, Ogden CW, Emberton M. Visually directed high-intensity focused ultrasound for organ-confined prostate cancer: a proposed standard for the conduct of therapy. BJU Int 2006;98:1187-92.

7. Elliott SP, Meng MV, Elkin EP, McAninch JW, Duchane J, Carroll $\mathrm{PR}$, et al. Incidence of urethral stricture after primary treatment for prostate cancer: data From CaPSURE. J Urol 2007;178:529-34.

8. Besarani D, Amoroso P, Kirby R. Bladder neck contracture after radical retropubic prostatectomy. BJU Int 2004;94:1245-7.

9. Blana A, Walter B, Rogenhofer S, Wieland WF. High-intensity focused ultrasound for the treatment of localized prostate cancer: 5-year experience. Urology 2004;63:297-300.

10. Rebillard X, Soulie M, Chartier-Kastler E, Davin JL, Mignard JP, 
Moreau JL, et al. High-intensity focused ultrasound in prostate cancer; a systematic literature review of the French Association of Urology. BJU Int 2008;101:1205-13.

11. Giannarini G, Manassero F, Mogorovich A, Valent F, De Maria M, Pistolesi D, et al. Cold-knife incision of anastomotic strictures after radical retropubic prostatectomy with bladder neck preservation: efficacy and impact on urinary continence status. Eur Urol 2008;54: 647-56.

12. Westney OL. Salvage surgery for bladder outlet obstruction after prostatectomy or cystectomy. Curr Opin Urol 2008;18:570-4.

13. Kumar P, Nargund VH. Management of post-radical prostatectomy anastomotic stricture by endoscopic transurethral balloon dilatation. Scand J Urol Nephrol 2007;41:314-5.

14. Surya BV, Provet J, Johanson KE, Brown J. Anastomotic strictures following radical prostatectomy: risk factors and management. J Urol 1990;143:755-8.

15. Popken G, Sommerkamp H, Schultze-Seemann W, Wetterauer U, Katzenwadel A. Anastomotic stricture after radical prostatectomy. Incidence, findings and treatment. Eur Urol 1998;33:382-6.

16. Eltahawy E, Gur U, Virasoro R, Schlossberg SM, Jordan GH. Management of recurrent anastomotic stenosis following radical prostatectomy using holmium laser and steroid injection. BJU Int 2008; 102:796-8.

17. Lagerveld BW, Laguna MP, Debruyne FM, De La Rosette JJ. Holmium:YAG laser for treatment of strictures of vesicourethral anastomosis after radical prostatectomy. J Endourol 2005;19:497501.

18. Begg CB, Riedel ER, Bach PB, Kattan MW, Schrag D, Warren JL, et al. Variations in morbidity after radical prostatectomy. $\mathrm{N}$ Engl J Med 2002;346:1138-44.

19. Dalkin BL. Endoscopic evaluation and treatment of anastomotic strictures after radical retropubic prostatectomy. J Urol 1996;155: 206-8.

20. Vicente J, Salvador J, Caffaratti J. Endoscopic urethrotomy versus urethrotomy plus Nd-YAG laser in the treatment of urethral stricture. Eur Urol 1990;18:166-8.

21. Gurdal M, Tekin A, Yucebaş E, Kirecci S, Sengor F. Contact neodymium: YAG laser ablation of recurrent urethral strictures using a side-firing fiber. J Endourol 2003;17:791-4.

22. Ramli R, Durand D, Fried NM. Subsurface tissue lesions created using an Nd:YAG laser and cryogen cooling. J Endourol 2003;17: 923-6.

23. Larizgoitia I, Pons JM. A systematic review of the clinical efficacy and effectiveness of the holmium:YAG laser in urology. BJU Int 1999;84:1-9.

24. Kamp S, Knoll T, Osman MM, Kohrmann KU, Michel MS, Alken P. Low-power holmium:YAG laser urethrotomy for treatment of urethral strictures: functional outcome and quality of life. J Endourol 2006;20:38-41.

25. Dogra PN, Ansari MS, Gupta NP, Tandon S. Holmium laser corethrough urethrotomy for traumatic obliterative strictures of urethra: initial experience. Urology 2004;64:232-5.

26. Choi SH, Lee YS, Choi NG, Kim HJ. Initial experience with endoscopic holmium: YAG laser urethrotomy for incomplete urethral stricture. Korean J Urol 2009;50:246-50.

27. Atak M, Tokgoz H, Akduman B, Erol B, Donmez I, Hancı V, et al. Low-power holmium:YAG laser urethrotomy for urethral stricture disease: comparison of outcomes with the cold-knife technique. Kaohsiung J Med Sci 2011;27:503-7.

28. Yurkanin JP, Dalkin BL, Cui H. Evaluation of cold knife urethrotomy for the treatment of anastomotic stricture after radical retropubic prostatectomy. J Urol 2001;165:1545-8. 